W Sakamoto and S Stowasser are employees of Boehringer Ingelheim.

WA Wuyts reports grants from Boehringer Ingelheim, grants from Roche, outside the submitted work.

\section{M33 LONG-TERM EFFICACY OF NINTEDANIB IS MAINTAINED IN PATIENTS WITH IDIOPATHIC PULMONARY FIBROSIS (IPF) IRRESPECTIVE OF DOSE: SUBGROUP ANALYSIS OF INPULSIS-ON}

10.1136/thoraxjnl-2017-210983.477

B Crestani reports personal fees and non-financial support from astra-zeneca, grants, personal fees and non-financial support from boehringer ingelheim, non-financial support from cardif, non-financial support from lvl, personal fees and nonfinancial support from apelis, grants from medImmune, personal fees and non-financial support from sanofi, outside the submitted work.

M Kolb reports grants and personal fees from Boehringer Ingelheim, during the conduct of the study; grants and personal fees from Roche, grants and personal fees from Boehringer Ingelheim, personal fees from GSK, personal fees from Gilead, grants from Actelion, grants from Respivert, personal fees from Astra Zeneca, personal fees from Prometic, personal fees from Genoa, grants from Canadian Institute for Health Research, grants from Canadian Pulmonary Fibrosis Foundation, outside the submitted work.

B Wallaert: No conflict of interest

M Quaresma and W Stansen are employees of Boehringer Ingelheim.

L Richeldi reports grants and personal fees from Boehringer Ingelheim, during the conduct of the study; grants and personal fees from InterMune, personal fees from Medimmune, personal fees from Biogen-Idec, personal fees from Sanofi-Aventis, personal fees from Roche, personal fees from Takeda, personal fees from ImmuneWorks, personal fees from Shionogi, outside the submitted work.

\section{M34}

CARDIOVASCULAR SAFETY OF NINTEDANIB IN SUBGROUPS BY CARDIOVASCULAR RISK AT BASELINE IN THE TOMORROW AND INPULSIS TRIALS

10.1136/thoraxjnl-2017-210983.478

I Noth reports grants and personal fees from Boehringer Ingelheim, grants and personal fees from Genentech, personal fees from ImmuneWorks, personal fees from Sanofi, outside the submitted work.

$M$ Wijsenbeek reports an unrestricted research grant and speaker and advisory board fees from InterMune/Hoffman-La Roche, an unrestricted research grant and speaker and advisory board fees from Boehringer Ingelheim, speaker and advisory board fees from Galapagos, outside the submitted work.

$\mathrm{M}$ Kolb reports grants and personal fees from Boehringer Ingelheim, during the conduct of the study; grants and personal fees from Roche, personal fees from GSK, personal fees from Gilead, grants from Actelion, grants from Respivert, personal fees from Astra Zeneca, personal fees from Prometic, personal fees from Genoa, grants from Canadian Institute for Health Research, grants from Canadian Pulmonary Fibrosis Foundation, outside the submitted work.

F Bonella reports grants and non-financial support from Boehringer Ingelheim, grants and non-financial support from Roche, outside the submitted work.

L Moros and Dr Wachtlin are employees of Boehringer Ingelheim.

TJ Corte reports an unrestricted educational grant, speaker and advisory board fees from Boehringer Ingelheim, an unrestricted educational grant, speaker and advisory board fees from Roche, advisory board fees from Astra Zeneca, an unrestricted educational grant from Actelion, an unrestricted education grant from Bayer, an unrestricted educational grant from BMS, an unrestricted educational grant from Sanofi, outside the submitted work. 